\title{
Development and psychometric testing of the nursing student satisfaction scale for the associate nursing programs
}

\author{
Hsiu-Chin Chen ${ }^{1}$, Huan-Sheng Lo ${ }^{2}$ \\ 1. Department of Nursing, Utah Valley University, Utah, United States. 2. Department of Behavior Science, Utah Valley \\ University, Utah, United States.
}

Correspondence: Hsiu-Chin Chen. Address: Department of Nursing, Utah Valley University. 800 West University Parkway, MS 172, Orem, Utah 84058. Telephone: 801-863-6096. Fax: 801-863-6093. E-mail: chenhs@uvu.edu

Received: December 28, $2011 \quad$ Accepted: January 11, $2012 \quad$ Published: August 1, 2012

DOI : $10.5430 /$ jnep.v2n3p25

URL: http://dx.doi.org/10.5430/jnep.v2n3p25

\section{Abstract}

Background: The purpose of this nationwide study was to assess psychometric properties of the Nursing Student Satisfaction Scale (NSSS) for measuring student satisfaction with nursing programs.

Methods: This methodological study addressed the development, evaluation, and validation of a newly developed instrument using a cross-sectional design. Proportionally stratified random sampling was utilized to select 138 Associate in Science in Nursing (ASN) programs for participation.

Results: Evidence of psychometric evaluation indicated that the internal consistency reliability was consistently acceptable throughout a previous 3-year psychometric evaluation study to this methodological study. The Curriculum and teaching, Professional social interaction, and Environment (CPE) 3-factor model of the NSSS was suggested by the exploratory factor analysis and was supported by the confirmatory factor analysis based on the results of "goodness-of-fit" test.

Conclusions: The NSSS demonstrates sound psychometric properties and provides a theory-based approach to the measurement of nursing student satisfaction.

\section{Key words}

Psychometric evaluation, Nursing student satisfaction, Exploratory factor analysis, Confirmatory factor analysis

\section{I ntroduction}

Program evaluation in higher education has been emphasized as a way of improving learning and demonstrating accountability ${ }^{[1,2]}$. Accountability indicators, such as overall student satisfaction, have provided critical information regarding the attractiveness of the college to students ${ }^{[3]}$. Research has indicated that the inclusion of student satisfaction measures in a comprehensive program evaluation may provide insights into the total educational experience for students and an understanding of student expectations for program development and enhancement ${ }^{[1,4]}$. Thus, there is a need for using a reliable and valid instrument to comprehensively explore areas of the nursing program that students are mostly satisfied with. 
A search of literature revealed no single, widely-accepted and easily accessible student satisfaction questionnaires for nursing students; and little evidence has been provided to demonstrate consistent assessment of psychometric properties of an instrument for measuring nursing student satisfaction with the nursing program. The purpose of this national survey study was to consistently assess psychometric properties of the Nursing Student Satisfaction Scale (NSSS) for measuring student satisfaction with nursing programs. The research questions were: (1) What are Cronbach's alphas, inter-item correlation coefficients, and the corrected item-total correlation coefficients of the NSSS according to item analysis for internal consistency reliability? (2) What is the construct validity of the NSSS using exploratory and confirmatory factor analyses?

\subsection{Literature review}

Over the past decade, there has been growing evidence of the need for evaluation of the quality of nursing education for greater accountability because of the demands required by healthcare institutions and consumers ${ }^{[5]}$. Research indicates there is evidence supporting student satisfaction measurement with increased student engagement and retention in higher education ${ }^{[6,7]}$. Institutions such as Educational Benchmarking, Inc. (EBI), in partnership with the American Association of Colleges of Nursing (AACN), has developed various measures of Nursing Education Assessments to evaluate the effectiveness of undergraduate and graduate nursing programs based on students' perspectives ${ }^{[8]}$. Organizations responsible for accreditation of nursing education programs in the US, such as the National League for Nursing Accrediting Commission (NLNAC), which accredits all levels of nursing education, require nursing education programs to measure, report, and utilize student satisfaction data as an indicator of educational effectiveness ${ }^{[9]}$.

A review of international studies regarding nursing student satisfaction with their nursing programs notes recommendations similar to studies conducted in the US. Two studies ${ }^{[10,11]}$ indicated that there was a need for improving the quality of the nursing program. Cowman's ${ }^{[12]}$ study provided feedback to nursing schools regarding student perceptions of the quality of learning such as good teaching, clear goals, and appropriate workload. Particularly, a national study conducted in Norway by Weirs-Jenssen et al. ${ }^{[4]}$ proposed that social climate and aesthetic aspects of the physical infrastructure should be considered when improving student satisfaction levels.

The use of standardized questionnaires to measure student satisfaction with the nursing program as a whole has provided an awareness to identify what program features and facilities are necessary to enhance program success and where change is needed ${ }^{[11]}$. Although accrediting bodies and research evidence have proposed student satisfaction being viewed as one of the program outcomes ${ }^{[9,13]}$, nursing student satisfaction has not been sufficiently studied in the US; neither has any tool that consistently provides rigorous assessment of psychometric properties for measuring nursing student satisfaction.

A literature review of instruments was undertaken in order to address the need of a tool that was developed based on a comprehensive conceptual framework for understanding student satisfaction with the nursing program in this study. Marsh's ${ }^{[14]}$ Students' Evaluations of Educational Quality (SEEQ) and Ramsden's ${ }^{[15]}$ Course Experience Questionnaire (CEQ) were developed for examining student perceptions of the quality of teaching and curriculum. The SEEQ was used to measure nine aspects of effective teaching. The 30-item CEQ focused on the evaluation of five courses' experiences including good teaching, clear goals, appropriate workload, appropriate assessment, and independence. The content of the SEEQ and the CEQ was developed for the general student population and may not measure elements regarding the clinical practice that are critical for satisfaction among nursing students. Ansari's studies ${ }^{[16,17]}$ also focused on examining the perspectives of student satisfaction with modular courses in order to improve the quality of teaching and learning. Eighteen items in relation to the dimensions of module administration, module content, perception of module team, university resources, module assessment procedures, and module relevance were developed based on the work of several authors.

Liegler ${ }^{[18]}$ developed a path model consisting of the factors of external influences, college facilities and services, academic integration, and social integration to predict the overall satisfaction level of nursing students. The tool used to test the 
causal model was developed based on two instruments including the Social Integration with Peers Scale and the Social Integration with Faculty Scale developed by Pascarella and Terenzini ${ }^{[19]}$. These two instruments were originally developed in the late 1970s and may not accurately measure satisfaction in today's nursing students.

While instruments have been utilized to assess students' satisfaction with their particular course, little evidence has been provided to evaluate students' experience of the program as a whole ${ }^{[20]}$. Moreover, there was a lack of consistency in research related to evaluation of psychometric properties of the instrument used for measuring nursing student satisfaction, as well as a supportive model or a theory of student satisfaction specifically related to nursing education ${ }^{[21]}$. Some of the instruments in the literature were outdated and focused only on curriculum and teaching, which may not reflect the complexities of measuring and understanding the factors that influence satisfaction in current nursing students.

\subsection{Conceptual framework}

After conducting a series of discussions and literature reviews regarding a comprehensive student satisfaction appraisal, a conceptual framework of Curriculum, Faculty, Social Interaction, and Environment (CFSE) was developed by the principal investigator to describe the factors in measuring nursing student satisfaction. The CFSE conceptual framework was synthesized according to several concepts from literature reviews ${ }^{[9,10,15-18,20,22,23]}$ and was intended to illustrate the concept of student satisfaction broadly, as opposed to focusing on a specific aspect such as teaching or courses. Central to the CFSE conceptual framework is the belief that student satisfaction evolves in a dynamic process, which is influenced by the interaction between the student-faculty and teaching-learning environment. In this conceptual framework, student satisfaction with the nursing program is proposed to be directly affected by four major constructs: the content and structure of curriculum, faculty teaching strategies, social interaction among students and faculty, and the learning environment such as a nursing laboratory ${ }^{[24]}$.

\subsection{Procedures for the NSSS development}

\subsubsection{Description and scoring of the NSSS}

The Nursing Student Satisfaction Scale (NSSS) is used to measure nursing student satisfaction with the nursing program. The NSSS is a 31-item questionnaire using a 6-point Likert scale scored from $1=$ not satisfied at all to $6=$ very satisfied. The greater score indicates a higher level of student satisfaction with the nursing program. The NSSS includes four subscales based on the CSFE conceptual framework: 9 items related to curriculum, 8 items related to faculty, 6 items related to social interaction, 7 items related to environment, and one item for overall student satisfaction.

\subsubsection{Process of developing the NSSS}

The NSSS developed by our research team was used to measure nursing student satisfaction with the nursing program in this study. The process of developing the NSSS included the following steps and is briefly explained as follows ${ }^{[24]}$. (1) Item development: initially our research team generated 47 items based on the CFSE conceptual framework. The item development was through a process of mutual collaboration involving repeated review, critique, and revision; (2) $\mathrm{Q}$ methodology for selecting items: a convenience sample of 18 Associate Degree in Nursing (ADN) students were asked to sort the initial 47 items into seven piles, scored from $1=$ least important to $7=$ most important; (3) A focus group of nursing faculty: 11 nursing faculty members were directed to individually select the eight most important items for each subscale of the NSSS. Forty items were then retained based on the results of items selected by the nursing students and faculty; and (4) An expert panel review for content validation: Four expert educators with backgrounds in nursing, administration, or teaching and learning at the university were invited to develop content validity for the NSSS. A percentage score of the averaged congruency percentage (ACP) among the four experts was .96 for relevance, .97 for representativeness, and .93 for clarity, which were collectively above .90 , indicating acceptable items for the NSSS ${ }^{[25]}$. Based on the comments provided by the expert panel, the final version of the NSSS was a 31-item scale. 


\subsubsection{A 3-year psychometric evaluation}

A convenience sample of 51 nursing students who were in the final semester of the ADN program at the university was recruited for a pilot test. After the pilot study, a 3-year study for psychometric evaluation including item analysis, internal consistency reliability, and exploratory factor analysis was subsequently conducted using the data of 303 ADN students. For item analysis, the corrected item-total correlation coefficients of each subscale were greater than .45 , which indicates items contributing to the NSSS were acceptable. The inter-item correlation coefficients of each subscale were equal to or greater than .30 and less than .80 . The Cronbach's alphas of the 30 items were .93 for the total scale, and .85 for the curriculum, .87 for the faculty, .88 for the social interaction, and .86 for the environment subscale ${ }^{[24]}$.

A principal components factor analysis (PCA) with varimax rotation was conducted to examine construct validity. Factors were extracted based on the results of a scree plot, eigenvalues, total variance, and the conceptual consideration ${ }^{[26]}$. A cutting point of . 40 was used for factor loading, and the minimum eigenvalue of 1.0 was determined for retaining items. Although the PCA solution yielded three merged factors instead of the original four factors, all items of the NSSS were retained. We decided that the NSSS needs further evaluation of construct validity using a larger sample size with a heterogeneous background in the following study. In particular, confirmatory factor analysis had not been conducted to validate the framework.

\section{Subjects and methods}

This methodological study addressed the development, evaluation, and validation of a newly developed instrument using a cross-sectional design. The entire study procedure consisted of three stages. Stage I was for developing the NSSS, and stage II was a 3-year longitudinal psychometric evaluation of the NSSS. Stages I and II were completed and the detailed report about the development process and the 3-year psychometric evaluations of the NSSS has been accepted for publication ${ }^{[24]}$. Stage III, which was this current study, a nationwide survey was conducted to use a larger sample with a heterogeneous background to evaluate the substantively generated CFSE framework using exploratory and confirmatory factor analyses in order to validate the dimensions. Before conducting this study, approval was granted by the universities' Institutional Review Board.

\subsection{Population and sample}

During the 2007 academic year, 50 states in the US offered 618 Associate in Science in Nursing (ASN) or Associate Degree in Nursing (ADN) programs accredited by the NLNAC. The ASN or ADN program in the US offers preparation for practice as a registered nurse and may serve as a basis for further nursing education. The ASN or ADN graduate is eligible to apply to each State Board of Nursing for licensure as a registered nurse (RN). The inclusion criterion for participating in this study was each state had a minimum of two schools of nursing offering ASN or ADN program accredited by the NLNAC but the program that offered on-line classes was excluded from this study. In total, 46 states were eligible for participation.

A roster of $615 \mathrm{ASN}$ or ADN programs from the 46 states was collected for sampling. To ensure representativeness from all states in term of the number of programs in each state, proportionally stratified random sampling was utilized to randomly select $138 \mathrm{ASN}$ or ADN programs for participation, and 31 states producing 56 ASN or ADN programs agreed to participate in this study. The method for sampling was (1) two nursing programs were randomly selected from each state having equal to or below 10 nursing programs offering ASN or ADN programs; and (2) four and six nursing programs were randomly selected from a state with 11 to 20 ASN or ADN programs and a state having 21 to above 40 nursing programs, respectively. Both female and male nursing students who registered in the final semester of spring 2009 or fall 2008 in the ASN or ADN program were invited to participate in this study. There were no requirements regarding students' race, gender, age, and ethnicity for participation. 


\subsection{Data collection procedures}

A pre-survey invitation letter and a cover letter were sent via e-mail to all of the chairs of the selected nursing programs to explain the purpose of this study, the risks and the benefits, and the voluntary nature of participation. After obtaining the permission of participation from each selected nursing program, questionnaire packets were mailed to the chairs at the school address either in the spring semester or fall semester. The chair of the selected ASN or ADN programs and the principal investigator ensured that each student was fully aware of the objectives of the study and that each student voluntarily participated in this study. The questionnaires were answered anonymously by nursing students who were in the final semester of the selected ASN or ADN program and were completed during a regularly scheduled nursing class. The chair was responsible for returning completed questionnaires to the investigator by mail without any way to identify the nursing students.

\subsection{Data analysis methods}

All data were entered into and analyzed by the Statistical Package for the Social Science (SPSS) for Windows and the AMOS, version 17.0. Summary statistics of demographic data were computed according to data levels. Independent t-test and Chi-Square test were performed according to data levels to examine the similarity of students' demographics between the samples of fall semester and spring semester. Before further data analysis, missing data, skewness, and outliers were examined and managed. The internal consistency reliability of the NSSS was assessed using Cronbach's $\alpha$. The inter-item correlation coefficients and the corrected item-total correlation coefficients of item analysis were computed to examine the multicollinearity of the NSSS. The item selection criteria for the NSSS included (1) acceptable coefficients for item-total correlations are greater than .30 , which indicate items contributing to the measure; (2) the coefficients of inter-item correlations between .30 and .80 are acceptable, which coefficients greater than .80 indicate redundant items because of multicollinearity and coefficients less than .30 indicate items that are insufficiently related; and (3) the coefficients of Cronbach's $\alpha$ do not decrease substantially when an item is deleted ${ }^{[27]}$. Item analysis and Cronbach's $\alpha$ were recomputed when the items were removed.

Exploratory factor analysis (EFA) for construct validity was computed to validate the constructs of the NSSS. Factors were extracted based on the results of (1) Bartlett's test of sphericity for testing the hypothesis that the correlation matrix is an identity matrix; (2) Kaiser-Meyer-Olkin test (KMO) for measuring sampling adequacy; (3) a scree plot for determining the number of factors by identifying distinct breaks in the slope of the plot; (4) the eigenvalue $(\lambda)>1.0$ for representing the amount of variance in all of the items that can be explained by a given factor; (5) a cutting point $\geqslant .40$ for factor loading for retaining items; and (6) the conceptual consideration for placing items with the factor ${ }^{[26]}$.

Confirmatory factor analysis (CFA) for construct validity was used to evaluate whether the factor model derived from the EFA was valid and was computed using AMOS 17. Assumptions such as multivariate normality and a large sample size for maximum likelihood (ML) CFA was diagnosed for items and subscale scores of the NSSS. A comparative fit index (CFI) value of .90 or greater has served as a lower limit rule-of-thumb cut-off for acceptable model fit. The CFI is equal to the discrepancy function adjusted for sample size. The model's goodness-of-fit was indicated by (1) the ratio of Chi-square to degrees of freedom $\left(\mathrm{CMIN} / \mathrm{DF}=\chi^{2} / d f\right)$ between 2 and 5 ; (2) the root-mean-square error of approximation (RMSEA) addresses how well the model would fit the population correlation matrix if it were available. The RMSEA less than .05 with a 90\% confidence interval (CI) value represents a good degree of precision; (3) the goodness-of-fit index (GFI) and the adjusted GFI (AGFI) values not less than .90 , and (4) the normed fit index (NFI) value close to $0.95^{[28]}$.

\section{Results}

\subsection{Demographic characteristics of samples}

Fifty-six ASN or ADN programs accredited by the NLNAC from 31 states in the US completed this study and produced $76 \%$ response rate. In total, 823 senior ASN or ADN students who graduated in fall semester 2008 and 1,152 senior ASN 
or ADN students who graduated in spring semester 2009 participated in this national study. No significant differences in demographics were reported between these two semesters' participants. Most of the total 2,020 participating students were white and non-Hispanic $(n=1,590,79.1 \%)$. There were $11.2 \%(n=227)$ males and $88.8 \%(n=1,791)$ females. The average age of the students was 31 years old. The majority were married $(n=921,45.8 \%)$ and employed $(n=1,417,70.5 \%$, see Table 1).

Table 1. Demographic Characteristics of Samples $(\mathrm{N}=2,020)$

\begin{tabular}{|c|c|c|}
\hline Demographic variable & $\mathbf{n}$ & $\%$ \\
\hline \multicolumn{3}{|l|}{ Gender* } \\
\hline Female & 1791 & 88.8 \\
\hline Male & 227 & 11.2 \\
\hline \multicolumn{3}{|l|}{ Marital status ${ }^{*}$} \\
\hline Married & 921 & 45.8 \\
\hline Non-married & 891 & 44.4 \\
\hline Divorced & 197 & 9.8 \\
\hline \multicolumn{3}{|l|}{ Race $^{*}$} \\
\hline White, non Hispanic & 1590 & 79.1 \\
\hline Black, non Hispanic & 193 & 9.6 \\
\hline Hispanic & 92 & 4.6 \\
\hline American Indian/Alaskan Native & 5 & 0.2 \\
\hline Asian/Pacific islander & 91 & 4.5 \\
\hline Other & 39 & 1.9 \\
\hline \multicolumn{3}{|l|}{ Employment ${ }^{*}$} \\
\hline Employed part-time & 1055 & 52.5 \\
\hline Employed full-time & 362 & 18.0 \\
\hline Unemployed & 592 & 29.5 \\
\hline \multicolumn{3}{|l|}{ Type of employment ${ }^{*}$} \\
\hline PCT & 212 & 14.8 \\
\hline CNA & 264 & 18.4 \\
\hline LPN & 305 & 21.2 \\
\hline Other & 353 & 24.6 \\
\hline Non Nursing & 303 & 21.1 \\
\hline \multicolumn{3}{|l|}{ Other college degree ${ }^{*}$} \\
\hline Associate of Arts & 188 & 9.7 \\
\hline Bachelor of Arts & 143 & 7.4 \\
\hline Master of Arts & 12 & 0.6 \\
\hline Associate of Science: non nursing & 160 & 8.3 \\
\hline Bachelor of Science: non nursing & 131 & 6.8 \\
\hline None & 1285 & 66.5 \\
\hline \multicolumn{3}{|l|}{ Tuition and fee ${ }^{*}$} \\
\hline Self & 723 & 35.8 \\
\hline Parents and families & 229 & 11.3 \\
\hline Employer reimbursement & 103 & 5.1 \\
\hline Scholarship & 242 & 12.0 \\
\hline Student loan ${ }^{*}$ & 606 & 30.0 \\
\hline Other & 116 & 5.7 \\
\hline
\end{tabular}

*Variable had incomplete data.

Note. Patient Care Technician (PCT); Clinical Nursing Assistant (CAN); Licensed Practical Nurse (LPN) 


\subsection{Psychometric evaluation of the NSSS}

\subsubsection{I tem analysis}

The demographic data across each participating school were substantially similar; therefore, the data of all 823 senior ASN or ADN students who graduated in fall semester 2008 were merged for use in item analysis for the NSSS. The results of item analysis showed that the inter-item correlation coefficients of the 30 items in the four subscales were equal or greater than .30 and less than .80; and the corrected item-total correlation coefficients of all 30 items were all greater than .30. All items of the NSSS met the criteria for the inter-item and corrected item-total correlation coefficients, which indicated items contributing to the scale. For internal consistency reliability, the alpha of the total scale of the NSSS was .96 and each subscale was .91 for the curriculum, .90 for the faculty, .88 for the social interaction, and .87 for the environment.

\subsubsection{Exploratory factor analysis (EFA)}

In order to develop construct validity for the NSSS, a Principal Axis Factoring (PAF) with oblimin rotation was utilized for computing EFA using 823 senior ASN or ADN students who graduated in fall semester 2008 . The number of 823 participants met the ideal rule that ten times as many respondents as items for factor analysis ${ }^{[26]}$. Oblique rotation is used when there was evidence showing that the underlying factors are correlated ${ }^{[29]}$. It is reasonable to hypothesize that these factors are interacted and correlated to some extent under the conceptualization of the CFSE conceptual framework. The Kaiser-Meyer-Olkin (KMO) measure of sampling adequacy was .97 achieving the ideal value, which is above .80 and the determinant $(=.001)$ was small and close to zero indicating the data were legitimately factored ${ }^{[26,30]}$. Bartlett's test of sphericity was significant $\left(\chi^{2}=14476.55, p=.0001\right)$, which indicated that the correlation matrix was not an identity matrix. Five factors' eigenvalues were greater than one, and a discontinuity between the third and fourth factor was identified in the scree test. Therefore, three factors and four factors were individually forced to enter into the PAF analysis with oblimin rotation in order to identify appropriate factor constructs.

The 4-factor model accounted for $57.6 \%$ of the total variance. Seven items were deleted and 23 items demonstrated moderate to strong loadings $(>.40)$. The PAF with oblimin rotation was rerun to force three factors into analysis. The 3 -factor model explained $55.7 \%$ of the total variance. Twenty-seven items of the NSSS demonstrated moderate to strong loadings $(>.40)$, and three items were deleted (see Table 2). Comparing the pattern matrices of the 3- and the 4-factor models, the 3-factor model was selected for developing construct validity because the factors were well clustered with the consideration of theoretical conceptualization. The first factor was named "curriculum and teaching" and consisted of 13 items. The "environment" was the second factor and had five items. The third factor was "professional social interaction" and composed of nine items.

\subsubsection{Confirmatory factor analysis (CFA)}

In confirming the 3-factor model developed by the EFA, a structural equation modeling (SEM) analysis (AMOS, MLE) for CFA using the original NSSS solution indicated that all items loaded significantly on their specified subscales based on a PAF solution. The "model fit" of CFA was obtained based on the data of 1,152 senior ASN or ADN students who graduated in spring of 2009. Marcoulides ${ }^{[31]}$ stated that the application of CFA is highly beneficial as a follow-up to EFA but is applied on a different data set/sample with the same set of observed variables in the scale. The results of the CFA demonstrated an excellent overall fit for the 3-factor model $\left(\chi^{2} / d f=3.74\right.$, GFI $=.93$, AGFI $=.91, \mathrm{NFI}=.95, \mathrm{CFI}=.97$, $\mathrm{RMSEA}=.049, \mathrm{CI}=.046-.052$, see Figure 1). All coefficients of regression weights and covariances of the three factors were statistically significant $(p<.001)$. The RMSEA, one of the most popular and robust fit index, explained that the 3 -factor structure was a good fitting model because of the value less than $.05^{[28]}$.

As a result of yielding the new three factors, Cronbach's $\alpha$ and item analysis were rerun for the 27-item NSSS plus one item for overall student satisfaction. The corrected item-total correlation coefficients of each subscale were greater than 
.45. The inter-item correlation coefficients of each subscale were equal to or greater than .30 and less than .80 . The Cronbach's $\alpha$ of internal consistency was .94 for the curriculum and teaching, .93 for the professional social interaction, .89 for the environment, and .96 for the total scale.

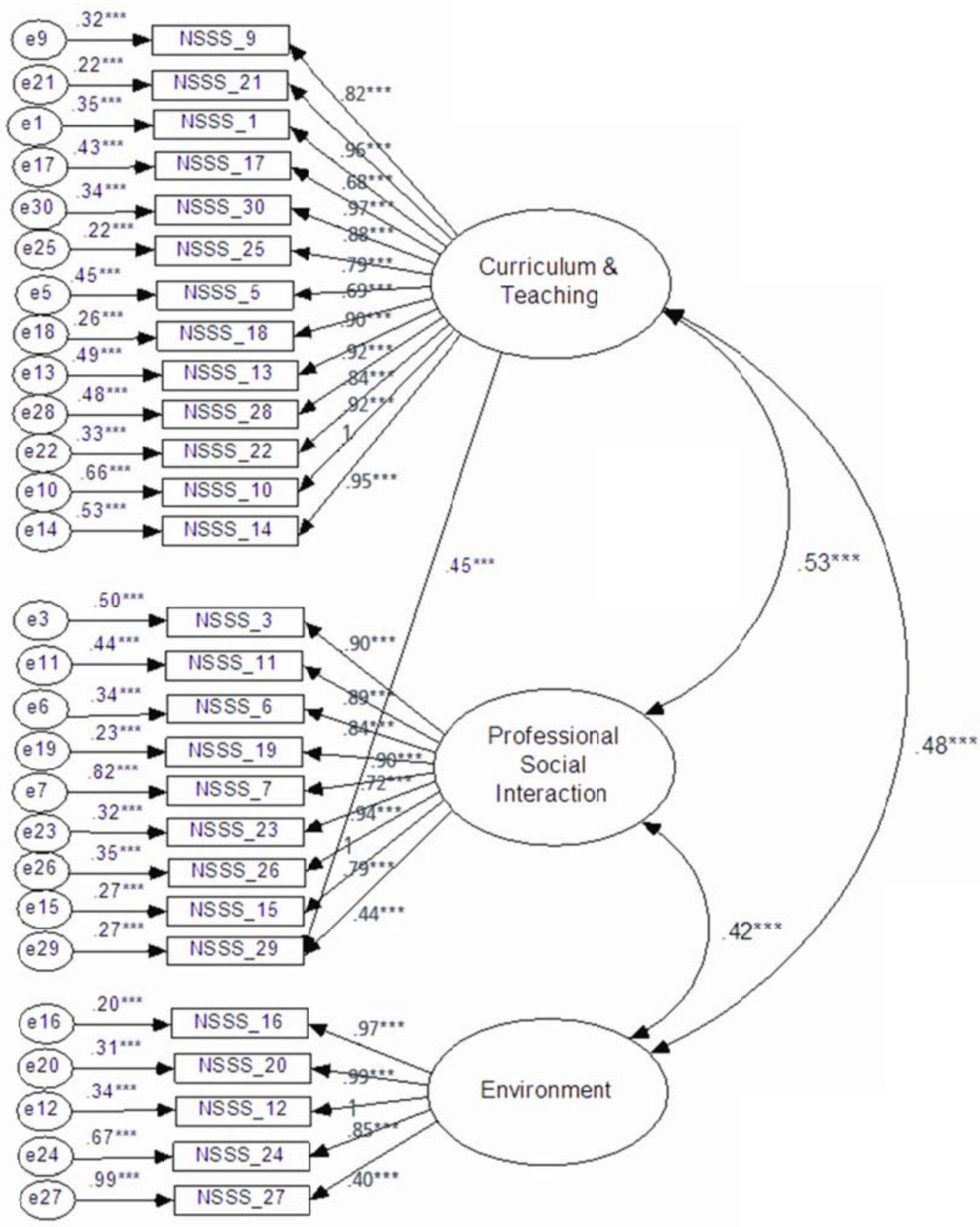

Figure 1. Structure of the 3-Factor NSSS Using Confirmatory Factor Analysis $* * * p<0.001$. 
Table 2. Factor Solution of the 27-Item Nursing Student Satisfaction Scale

\begin{tabular}{|c|c|c|}
\hline Factor/Item & Communalities & $\begin{array}{l}\text { Factor Loadings } \\
\text { Pattern Matrix }\end{array}$ \\
\hline Factor 1: Curriculum and Teaching & \multirow[t]{14}{*}{ Eigenvalue: 13.9} & $\%$ of variance: 46.3 \\
\hline NSSS 9: Prepared me to use the nursing process in my clinical practice & & .819 \\
\hline NSSS 21: Prepared me to become a professional nurse & & .816 \\
\hline NSSS 1: Enhanced my problem solving skills & & .737 \\
\hline NSSS 17: Prepared me to take the NCLEX-RN & & .732 \\
\hline NSSS 30: Progressed logically from simple to complex concepts & & .710 \\
\hline NSSS 25: Was relevant to current nursing practice & & .597 \\
\hline NSSS 5: Helped me improve my communication skills & & .589 \\
\hline NSSS 18: Effectively explained essential concepts & & .588 \\
\hline NSSS 13: Feel confident about my ability to practice in clinical settings & & .553 \\
\hline NSSS 28: The syllabus clearly described what was expected of me & & .529 \\
\hline NSSS 22: Made an effort to make their topics interesting & & .513 \\
\hline NSSS 10: Collaboratively worked with each other in their teaching & & .449 \\
\hline NSSS 14: Effectively used technology to enhance my learning & & \\
\hline Factor 2: Environment & \multirow[t]{6}{*}{ Eigenvalue: 1.9} & $\%$ of variance: 6.2 \\
\hline NSSS 16: The equipment in the nursing lab was in good repair & & .905 \\
\hline NSSS 20: There was sufficient equipment in the nursing lab & & .893 \\
\hline NSSS 12: The equipment in the nursing lab was up to date & & .870 \\
\hline NSSS 24: The nursing lab had ample space & & 640 \\
\hline NSSS 27: Library resources were adequate & & .412 \\
\hline Factor 3: Professional Social Interaction & \multirow[t]{10}{*}{ Eigenvalue: 1.0} & $\%$ of variance: 3.2 \\
\hline NSSS 3: Was respected by the nursing faculty & & .899 \\
\hline NSSS 11: Felt comfortable asking questions of nursing faculty & & .748 \\
\hline NSSS 6: Were positive role models of professional nursing & & .683 \\
\hline NSSS 19: Had positive professional interactions with my nursing faculty & & .652 \\
\hline NSSS 7: Was respected by the nursing staff in the clinical settings & & .551 \\
\hline NSSS 23: Felt trusted by my nursing faculty & & .529 \\
\hline NSSS 26: Were fair/unbiased in their assessment of my learning & & .457 \\
\hline NSSS 15: The nursing faculty encouraged my learning & & .444 \\
\hline NSSS 29: Had reasonable expectations of my performance & & .412 \\
\hline
\end{tabular}

*Extraction method: a Principal Axis Factor analysis with Oblimin rotation was conducted.

Note. The 27-item NSSS plus one item for overall student satisfaction

\section{Discussion}

\subsection{Psychometric properties of the NSSS}

Item analysis. The objectives of item analysis are to examine how each item relates to overall scale performance and to select a set of items that is more strongly related to the construct of underlying concepts ${ }^{[32]}$. All 27 items of the NSSS met the criteria set for the inter-item and the corrected item-total correlation coefficients, which indicated items contributing to the scale. The internal consistency reliability was used to provide a general estimate of how well all items in the NSSS consistently measure the same phenomenon. The NSSS demonstrated acceptable evidence of internal consistency reliability throughout the previous pilot study, the previous 3-year psychometric evaluation, and this current nationwide study, which the $\alpha$ of the total scale and each subscale were above .80 indicating a well-established and widely used instrument ${ }^{[33]}$.

Construct validity. Although the PAF with oblimin rotation of EFA was conducted to develop construct validity, several factor solutions were rotated and examined in order to satisfy the criteria for EFA. Eventually, the 3-factor model including curriculum and teaching, professional social interaction, and environment was selected for the NSSS because factors were well clustered and was theoretically meaningful. The original three factors of curriculum, faculty, and social 
interaction were merged into the two new factors of "curriculum and teaching" and "professional social interaction," the derived factors made conceptual sense and have been supported by the literature that most of instruments for measuring student satisfaction focused on examining student perceptions of the quality of teaching and curriculum ${ }^{[15,16]}$.

Three items, "the faculty were knowledgeable in their field", "the classroom had ample space", and "the classroom environment was comfortable" were deleted according to the selection criteria of EFA, item's correlation coefficients, and item clarity. The content of these items was likely to be unclear in directing answers. For example, the classroom environment may provide physical comfort or mental comfort. Item 27 "library resources were adequate" and item 29 "faculty had reasonable expectations of my performance" loaded closely between two factors and the distinction of factor loadings was less than $.15^{[30]}$. A determination was made to keep item 27 in the environment factor and item 29 in the professional social interaction factor because the items' theoretical meaning and classification was more consistent with the original conceptualizations.

Although EFA generates only a hypothesis about the structure of these variables in a scale, a subsequent application of CFA can test this hypothesis. The 3-factor model suggested by the EFA for the NSSS was supported by the CFA examined in this study. As the limitations with all goodness-of-fit indices, it is necessary to examine more than one to ensure that an adequately-fitting model has been produced ${ }^{[34]}$. For example, a very large sample size in this study might increase statistical power as well as increase the likelihood of rejecting a true model. Thus, the RMSEA and CFI that are less influenced by sample size were used in this study ${ }^{[28]}$. The RMSEA less than .05 with a $90 \%$ confidence interval (CI) value represented a good degree of precision; and the CFI value of .97 served as a lower limit rule-of-thumb cut-off for acceptable model fit. The grouping of items in the CFA remained the same as grouped in the EFA, with the exception of item 29 "faculty had reasonable expectations of my performance" loaded on both factors of "curriculum and teaching" and "professional social interaction". The CFA suggested that the model fit would be improved when item 29 was allowed to load on both factors. Thus, it is suggested that this item needs more specific wording in future studies.

\subsection{I nterpretation of the three new factors}

Due to the original 4-factor NSSS being collapsed into three factors, the CFSE framework was renamed as the Curriculum and teaching, Professional social interaction, and Environment (CPE) framework (see Figure 2). The CPE framework for supporting the NSSS was developed in an attempt to include areas most important to nursing students and faculty. The final NSSS consists of 28 items including one item for overall student satisfaction. Factor one, curriculum and teaching, combines all nine items of the original curriculum factor and four items of the original faculty factor. The name of "teaching" was added into the original curriculum factor because the items from the original faculty factor are more related to faculty's qualification and preparedness for teaching, such as "the nursing faculty effectively explained essential concepts." This factor is similar to the Course Experience Questionnaire developed by Ramsden ${ }^{[15]}$, which focused on curriculum's goals, clear vision of expected learning, and teaching strategies.

Factor two is composed of five items of the original environment factor. The name of this factor was not changed because it was well clustered. The environment factor emphasizes the evaluation of the resources and facilities of the nursing laboratory and library. Liegler ${ }^{[18]}$ proposed that environment such as the college's facilities and services have an impact on overall student satisfaction. Library resources are viewed as an essential intervention to influence student learning ${ }^{[16]}$.

Factor three, named "professional social interaction," consists of all six items of the original social interaction factor and three items from the original faculty factor. The professional social interaction factor refers to faculty and students' attitudes and attributes related to social interaction, such as mutual respect and trust. Liegler ${ }^{[18]}$ stated that the social integration factor could predict the overall nursing student satisfaction level. The student satisfaction scale used in Baykel et al.'s ${ }^{[10]}$ study also demonstrated the importance of social interaction between faculty and students such as "respect for students." 


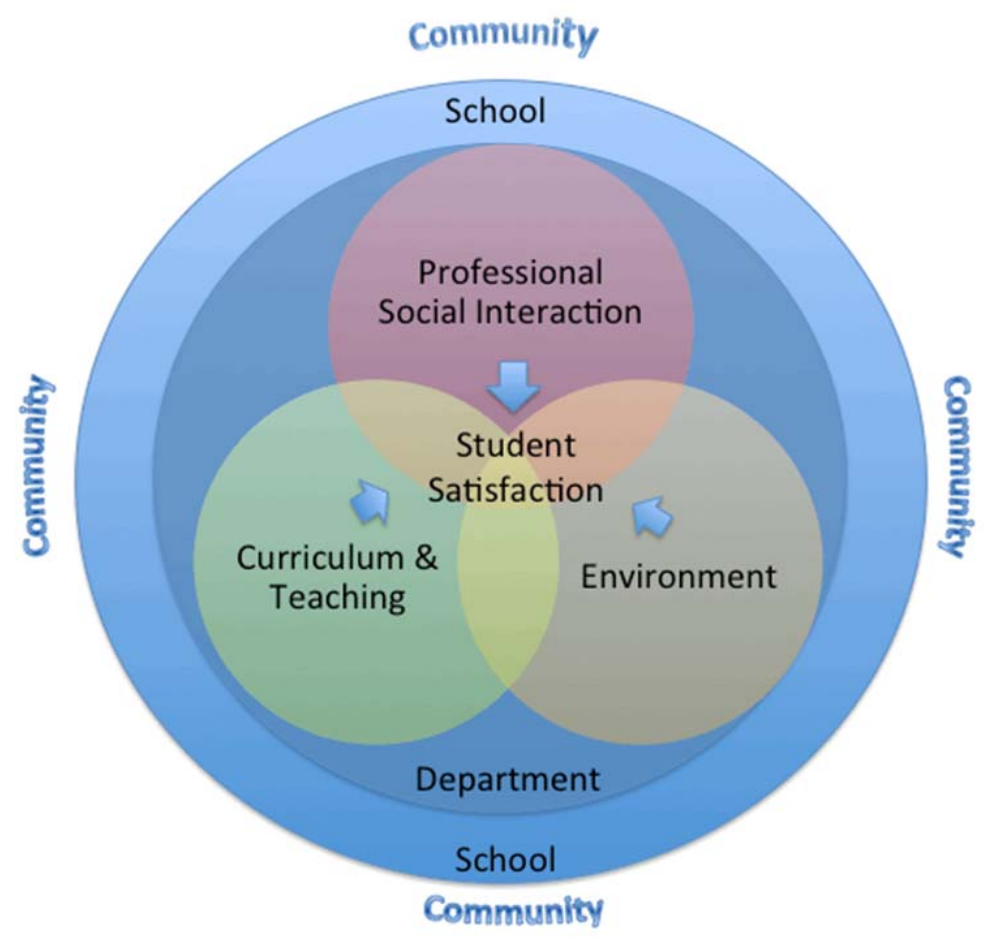

Figure 2. The CPE Conceptual Framework for Assessing Student Satisfaction: Curriculum and Teaching, Professional Social Interaction, and Environment

\subsection{Features of the NSSS related to nursing}

The NSSS demonstrates sound psychometric properties through a series of psychometric testing and uses a theory-based approach to construct the measurement of nursing student satisfaction. The NSSS provides a view that students perceive an effective learning environment when faculty develop and implement a climate of mutual respect and trust, collaboration, and supportiveness ${ }^{[35]}$. The curriculum and teaching factor of the NSSS has more emphasis on evaluating students' problem solving skills and communication skills throughout the curriculum in order to identify meeting the needs of clinical practice. Also, this factor specifies the evaluation of student performance prepared for graduation, such as the items "prepared me to take the NCLEX-RN" and "ability to practice in clinical." These items are supported by Cowman's ${ }^{[12]}$ study that adopting student performance as an evaluation indicator can maximize the accountability of the nursing education.

\section{Conclusion}

This study extends the previous 3-year psychometric evaluation study by using a larger sample with varied backgrounds to obtain the modified 3-factor NSSS. The 3-factor new structure was supported and validated by the CFA based on the results of "goodness-of-fit" test. The results support the theoretical view of the CPE that nursing student satisfaction is best conceptualized as multidimensional. The potential limitation of the study was that $54.4 \%$ of the participants were licensed practical nurses, clinical nursing assistants, and patient care technicians and it is possible those students may have differing perceptions and values when compared to generic nursing students. Furthermore, the NSSS may expand its applicability to the Bachelor of Science in Nursing (BSN) students and schools not accredited by the NLNAC in future studies. Reports of psychometric evaluations using data from BSN programs accredited by the Commission on Collegiate Nursing Education (CCNE) will be published elsewhere. Although a standardized measurement of student satisfaction provides faculty with 
information necessary to enhance students' educational experiences, various measures including qualitative and quantitative methods are suggested to be included in program evaluations.

\section{Presentation at a meeting}

Organization: Western Institute of Nursing (WIN) 43rd Annual Communicating Nursing Research Conference

Place: Glendale, Arizona

Date: April $14-17,2010$

\section{References}

[1] Brown JF, Marshall B. Continuous quality improvement: An effective strategy for improvement of program outcomes in a higher education setting. Nursing Education Perspectives. 2008; 29(4): 205-11. PMid:18770948

[2] Story L, Butts JB, Bishop SB, Green L, Johnson K, Mattison H. Innovative strategies for nursing education program evaluation. Journal of Nursing Education. 2010; 49(6): 351-3. PMid:20210284 http://dx.doi.org/10.3928/01484834-20100217-07

[3] Matthiesen V, Wilhelm C. Quality outcomes and program evaluation in nursing education: An overview of the journey. Quality Management in Health Care. 2006; 15(4): 279-84. PMid: 17047502

[4] Weirs-Jenssen J, Stensaker B, Grogaard JB. Student satisfaction: Towards an empirical deconstruction of the concepts. Quality in Higher Education. 2002; 8(2): 183-95. http://dx.doi.org/10.1080/1353832022000004377

[5] Suhayda R, Miller JM. Optimizing evaluation of nursing education programs. Nurse Educator. 2006; 31(5): 200-6. PMid:16980822 http://dx.doi.org/10.1097/00006223-200609000-00005

[6] Educational Benchmarking I. AACN/EBI nursing benchmarking assessments [Internet]. Available from: http://www.webebi.com/assessments/nursing.

[7] NLNAC. Accreditation manual: Assuring quality for the future of nursing education. NY: National League for Nursing Accrediting Commission, Inc. 2008.

[8] Espeland V, Indrehus O. Evaluation of students' satisfaction with nursing education in Norway. Journal of Advanced Nursing. 2003; 42(3): 226-36. PMid:12680966 http://dx.doi.org/10.1046/j.1365-2648.2003.02611.x

[9] The essentials of baccalaureate education for professional nursing practice [database on the Internet]. Commission on Collegiate Nursing Education [Internet]. 2008. Available from: http://www.aacn.nche.edu/Education/pdf/BaccEssentials08.pdf.

[10] Ramsden p. A performance indicator of teaching quality in higher education: The course experience questionnaire. Studies in Higher Education. 1991; 16(2): 129-51. http://dx.doi.org/10.1080/03075079112331382944

[11] Ansari WE. Student nurse satisfaction levels with their courses: Part I-effects of demographic variables. Nurse Education Today. 2002; 22: 159-70. PMid:11884197 http://dx.doi.org/10.1054/nedt.2001.0682

[12] Liegler RM. Predicting student satisfaction in baccalaureate nursing programs: Testing a causal model. Journal of Nursing Education. 1997; 36(8): 357-64. PMid:9348477

[13] Pascarella ET, Terenzini PT. Predicting freshman persistence and voluntary dropout decisions from a theoretical model. Journal of Higher Education. 1980; 51(1): 60-75. http://dx.doi.org/10.2307/1981125

[14] Richardson JTE. Instruments for obtaining student feedback: A review of the literature. Assessment and Evaluation in Higher Education. 2005; 30(4): 387-415. http://dx.doi.org/10.1080/02602930500099193

[15] Jeffreys MR, Massoni M, O' Donnell M, Smodlaka I. Student evaluation of courses: Determining the reliability and validity of three survey instruments. Journal of Nursing Education. 1997; 36(8): 397-400. PMid:9348484

[16] Ansari WE. Student nurse satisfaction levels with their courses: Part II- effects of academic variables. Nurse Education Today. 2002; 22: 171-80. PMid:11884198 http://dx.doi.org/10.1054/nedt.2001.0683

[17] Baykal U, Sokmen S, Korkmaz S, Akgun E. Determining student satisfaction in a nursing college. Nurse Education Today. 2005; 25: 255-62. PMid:15885856 http://dx.doi.org/10.1016/j.nedt.2004.11.009

[18] Pascarella ET, Terenzini PT. Predicting freshman persistence and voluntary dropout decisions from a theoretical model. Journal of Higher Education. 2008; 51(1): 60-75. http://dx.doi.org/10.2307/1981125

[19] Floyd E, Lewis NC, Walker EH. Creating a learner-centered environment in nursing education: An immersion experience. Journal of Adult Education. 2010; 39(1): 11-7.

[20] Authors. Development and psychometric testing of the Nursing Student Satisfaction Scale. Nursing Education Perspectives. In press.

[21] Waltz CF, Strickland OL, Lenz ER. Measurement in nursing and health research. 3rd ed. New York: Springer. 2005.

[22] Pett MA, Lackey NR, Sullivan JJ. Making sense of factor analysis. Thousand Oaks, CA: Sage Publication, Inc. 2003. 
[23] Tabachnick BG, Fidell LS. Using multivariate statistics. 4th ed. Boston: Allyn \& Bacon. 2001.

[24] Byrne BM. Structural equation modeling with AMOS: Basic concepts, applications, and programming. New York, NY: Taylor \& Francis Group, LLC. 2001. PMid:15633776

[25] Mertler CA, Vannatta RA. Advanced and multivariate statistical methods. 3rd ed. Glendale, CA: Pyrczak publishin. 2005.

[26] Strickland OL. Using factor analysis for validity assessment: Practical considerations. Journal of Nursing Measurement. 2003; 11(3): 203-5. http://dx.doi.org/10.1891/jnum.11.3.203.61274

[27] Marcoulides GA. Introduction to psychometric theory. New York, NY: Taylor \& Francis Group. 2011.

[28] Nunnally JC, Bernstein IH. Psychometric theory. 3rd ed. New York: McGraw-Hill. 1994.

[29] Kerlinger FN, Lee HB. Foundations of behavioral research. 4th ed. New York, NY: Harcourt College Publishers. 2000. PMid:20196760

[30] Schumacker RE, Lomax RG. A beginner's guide to structural equation modeling. New York, NY: Taylor \& Francis group, LLC. 2004.

[31] Rowbotham MA. Teacher perspectives and the psychosocial climate of the classroom in a traditional BSN program. International Journal of Nursing Education Scholarship. 2010; 7(1): 1-14. PMid:8876425 http://dx.doi.org/10.2202/1548-923X.1808

[32] Cowman S. Student evaluation: A performance indicator of quality in nurse education. Journal of Advanced Nursing. 1996; 24: 625-32. http://dx.doi.org/10.1046/j.1365-2648.1996.23325.x 